\title{
Wunderlich syndrome - unusual complication of spontaneous renal haemorrhage
}

Keywords: wunderlich syndrome, subcapsular, neoplasms, renal, vasculitis, arteriosclerosis, rupture, renal, artery, aneurysm, hypovolemic

Abbreviations: WS, wunderlich syndrome; RAML, renal angiomyolipoma; MDCT, multidetector computed tomography

\section{Introduction}

Wunderlich syndrome (WS) is a rare condition characterized by a non-traumatic spontaneous acute renal hemorrhage into the subcapsular and perirenal spaces, found and described in this case. The WS is characterized by Lenk's triad: acute abdominal pain, mainly in the flank, palpable mass and hypovolemic shock. Renal neoplasms are common cause for WS, and renal angiomyolipoma (RAML) is the most prevalent. ${ }^{1}$ However, several other causes must be ruled out, including renal malignant neoplasm, vascular diseases (vasculitis, arteriosclerosis, rupture of the renal artery aneurysm), kidney infection, undiagnosed blood dyscrasia and anticoagulant therapy. ${ }^{2,3}$

\section{Case presentation}

A 50year old man went to the emergency service with an unspecific abdominal pain complaint. We performed a multidetector computed tomography (MDCT) of the abdomen, with and without iodinated intravenous contrast, that showed a hypodense nodule formation with regular and well delimited outlines, few heterogeneous foci and fat density $(-35 \mathrm{HU})$, sizing about $1.8 \mathrm{~cm}$ from the inferior pole of the left kidney (Figure 1). The patient was relieved of the pain and was discharged from hospital in the same day.

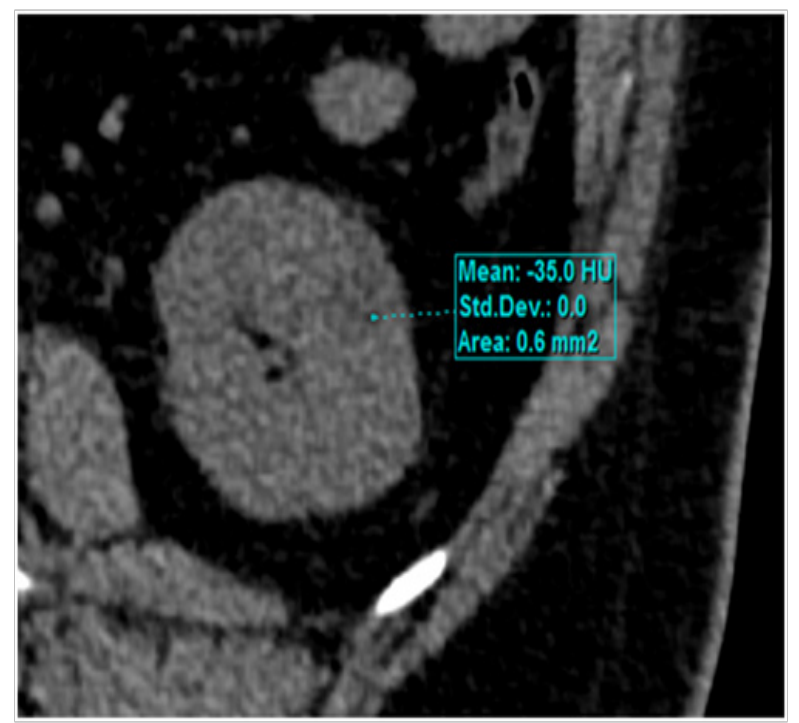

Figure I MDCT of left kidney without intravenous contrast, demonstrating nodular mass with $1.8 \mathrm{~cm}$ in the lower pole, with areas of fat density $(-35 \mathrm{HU})$.

After a month, the patient returned to the emergency service with a worse abdominal pain and an altered hemodynamic state. We
Volume 2 Issue I - 2017

\section{Clarice Gusmão dos Santos,' Joao Maurício Canavezi Indiani,' Marcelo Fontalvo Martin,' Marcelo Souto Nacif ${ }^{1,2}$ \\ 'Unidade de Radiologia Clínica/Hospital Vivalle, Brazil \\ ${ }^{2}$ Federal Fluminense University, Radiology Department, Brazil}

Correspondence: Marcelo Souto Nacif, Av. São João, Federal Fluminense University, Radiology Department, 2400 apto 232b 12242-000, São José dos Campos, SP - Brazil, Email msnacif@gmail.com

Received: December 23, 2016 | Published: January 03, 2017

performed another MDCT of the abdomen which detected the same nodule spontaneously dense and larger, with $2.2 \mathrm{~cm}$. We also detected an extend subcapsular renal and retroperitoneal hematoma, all aspects related to a spontaneous renal bleeding (Figure 2).
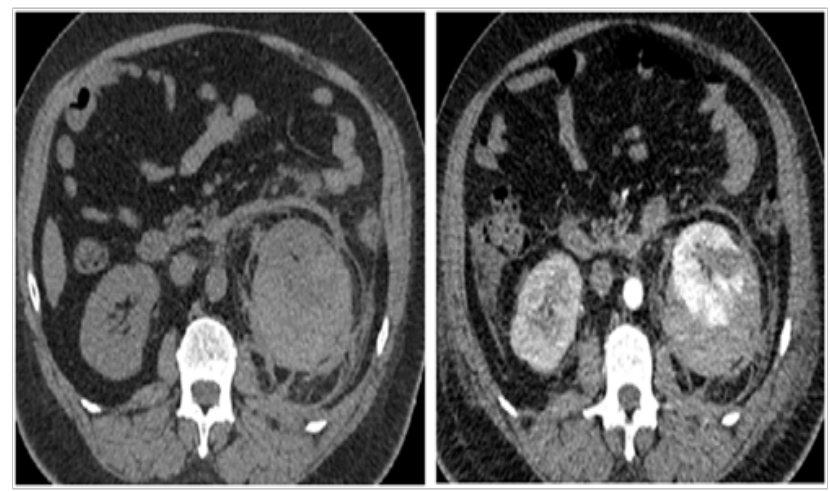

Figure 2A MDCT of the abdomen without intravenous contrast. Note spontaneously dense nodule associated with left renal subcapsular hemorrhage, and densification of adjacent fat.

Figure 2B MDCT during nephrographic contrast phase. Observe the low enhancement of the nodular area, similar to the first examination but slightly larger.

We choose a more conservative treatment with hemodynamic support and stabilization in an intensive care unit. The patient improved in the hemodynamic parameters, after a month of hospitalization and then hospital discharge, and remains in outpatient treatment with no complaints for 1year.

\section{Discussion}

The display of fat in a kidney tumor by MDCT, as described in the case, is very suggestive of a RAML. ${ }^{3}$ Other kidney tumors can also psent high levels of fat, such as the clear cell renal cell carcinoma, liposarcomas, atypical Wilms' tumor and teratomas. However, a cortical renal mass manly composed of fat (less than -20 HU) can be diagnosed as a RAML. ${ }^{4-6}$ 
The RAML is the most common benign renal tumor and typically consists of smooth muscle, blood vessels and adipose tissue. ${ }^{6} \mathrm{~A}$ tumor occurs as an isolated entity, sporadic in $80 \%$ of the cases, and generally manifests itself in middle aged women. The other $20 \%$ develops associated with tuberous sclerosis. The tendency for bleeding is multifactor and includes foci deficiency of the elastic tissue in abnormally rigid and thick blood vessels, hypervascularization and venous invasion. ${ }^{3,5,7}$

The spontaneous rupture of an angiomiolipoma is an infrequent urological emergency, although presenting a potential risk to life. ${ }^{8}$ The risk of bleeding is associated with a large tumor diameter. Tumors with less than $4 \mathrm{~cm}$ of diameter have less risk of bleeding. ${ }^{9}$ Our case did not have this usual aspect and was a relatively small tumor.

The proper choice of treatment depends on the clinical state of the patient, the laboratory results, the rupture degree of the kidney, and the size of the retroperitoneal bleeding. Many authors have argued that the WS can be treated in a conservative way if the hemorrhage is self-limited and the patient responsive to resuscitation fluids. ${ }^{5}$ Others recommend conservative treatment for RAML of less than $6 \mathrm{~cm}$ suggesting that only $34 \%$ of the patients with tumors bigger than 4 $\mathrm{cm}$ require intervention. ${ }^{9}$ In our case, the conservative treatment was our choice and is under serial and outpatient monitoring, with benign development for 1year.

MDCT is the best imaging test for WS, and the existence of RAML may be presumed and conservative therapy implemented. Arteriography with embolization is an important therapeutic method in the acute phase when necessary, as it controls the bleeding, and avoids surgery in a considerable number of patients. ${ }^{10}$

\section{Conclusion}

Despite rare, the WS must be immediately recognized through its findings in MDCT, regardless of its cause, because it can develop complications that can put the patient's life at risk. The radiologist has a fundamental role in diagnosis and in conservative therapeutic follow-up in these cases.

\section{Acknowledgements}

None.

\section{Conflict of interest}

Author declares that there is no conflict of interest.

\section{References}

1. Katabathina VS, Katre R, Prasad SR, et al. Wunderlich syndrome: crosssectional imaging review. J Comput Assist Tomogr. 2011;35(4):425-433.

2. Grassia M, Romano A, Esposito G, et al. A rare case of Wunderlich syndrome five days after left hemicolectomy for colorectal cancer. Int $J$ Surg Case Rep. 2015;16:33-36.

3. Nacif M. Carcinoma de células renais contendo gordura simulando angiomiolipoma: demonstração pela tomografia computadorizada e pela histopatologia. Radiol Bras. 2002;35(4):255-256.

4. Muglia VF, Prando A. Carcinoma de células renais: classificação histológica e correlação com métodos de imagem. Radiol Bras. 2015;48(3):166-174

5. Sotošek S, Markic D, Španjol J, et al. Bilateral Wünderlich Syndrome Caused by Spontaneous Rupture of Renal Angiomyolipomas. Case Rep Urol. 2015;1:1-3.

6. Catalano OA, Samir AE, Sahani DV, et al. Pixel distribution analysis: can it be used to distinguish clear cell carcinomas from angiomyolipomas with minimal fat? Radiology. 2008;247(3):738-746.

7. Helenon O, Merran S, Paraf F, et al. Unusual fat containing tumors of the kidney: a diagnostic dilemma. RadioGraphics. 1997;17:129-144.

8. Luis PBA, Bader SL, Bueno, et al. Ruptura de Angiomiolipoma Renal Gigante. Relato de Caso. J Bras Nefrol. 2008;30(3):226-229.

9. Kuusk T, Biancari F, Lane B, et al. Treatment of renal angiomyolipoma: pooled analysis of individual patient data. BMC Urol. 2015;15:123.

10. Albi G, del Campo L, Tagarro D. Wünderlich's syndrome: causes, diagnosis and radiological management. Clin Radiol. 2002;57(9):840-845. 